\title{
Diagnostic value of serum C-reactive protein as biomarker of cardiovascular risk in patients with type 2 diabetes
}

T.D. Cam ${ }^{1}$, T.A. Hoang ${ }^{1}$ H.T. Le ${ }^{1}$ H.V. Quyet ${ }^{2}$ P. T. Trung ${ }^{1}$, N.T. Binh and V.T.M. Thuc ${ }^{3}$

${ }^{1}$ Cardiology - Rheumatology - Endocrinology Department, Military

Hospital 175, Vietnam

${ }^{2}$ Hai Phong Medical University, Vietnam

${ }^{3}$ Tam Anh Hospital, Vietnam

Corresponding author: H.V. Quyet

E-mail: gsquyet@gmail.com

Genet. Mol. Res. 20 (1): gmr18730

Received December 30, 2019

Accepted April 20, 2020

Final Revision January 25, 2021

Published March 25, 2021

DOI http://dx.doi.org/10.4238/gmr18730

ABSTRACT. Diabetes mellitus (DM) continues to be the epidemic of the century and has a major impact on mortality from all causes and from cardiovascular disease (CVD). The systemic inflammatory pathway provides the common pathogenetic link in this comorbidity. We examined serum high- sensitivity C-reactive protein (hs-CRP) levels, as a marker of systemic inflammation in patients with type 2 diabetes mellitus and related them to CVD. The study consisted of 118 subjects with type 2 diabetes. Anthropometric characteristics were measured, and blood was collected for the evaluation of fasting blood sugar (FBS), HbAlc, and hs-CRP levels. Several clinical and biochemical characteristics were significantly different in the study group: triglycerides (TG), low-density lipoprotein cholesterol (LDL-C), highdensity lipoprotein cholesterol (HDL-C), compared to control levels. Mean age, body mass index (BMI) and waist circumference of subjects were 60.80 years, $35,2 \mathrm{~kg} / \mathrm{m}^{2}$, and $109.8 \mathrm{~cm}$, respectively. Increased HsCRP levels were positively correlated with increased BMI and HDL-C. No relationship was seen between Hs-CRP levels and systolic blood pressure, FBS level, HbAlc, Cholesterol, TG and LDL-C. Some cardiovascular risk factors (including gender, age, smoking, obesity, 
dyslipidemia, and hypertension) did not show correlation with serum hsCRP levels, while proteinuria did. Participants with cholesterol target levels had significantly lower hs-CRP. An association between hs-CRP and high cardiovascular risk is unlikely to be causal; however, hs-CRP could be a predictor for incidence of CVD in diabetic patients with comorbid obesity.

Key words: Hs-CRP; Diabetes mellitus; CVD; Lipid profile; Chronic inflammation

\section{INTRODUCTION}

Diabetes has become a global burden, and the prevalence in adolescents and young adults is increasing (World Health Organization, 2016). Evidence is accumulating that young-onset type 2 diabetes mellitus (T2DM) is more serious, leading to early development of complications, affecting quality of life, raising the possibility of a public health catastrophe (Lascar et al., 2018). Cardiovascular disease (CVD) is the leading cause of mortality in people with diabetes mellitus (DM); however, factors other factors are also important. Moreover, in people with diabetes, the vascular walls are more prone to damage, which are evident in the pre-diabetic stages, raising the possibility of vascular pathologies (Strain and Paldanius, 2018). Currently, the chronic systemic inflammation as a common pathogenetic link between DM and cardiovascular disease (CVD) appears to be firmly established (Diabetes Control and Complications, 2016; Nguyen et al., 2016; Ilyas et al., 2017). High-sensitivity C-reactive protein (hs-CRP) appears to contribute to the identification of people at risk of developing CVD. Some studies support the association of high baseline hs-CRP levels with high cardiovascular risk (Morrow et al., 2000). The CRP concentration might reflect the vulnerability of the atheromatous lesion and the likelihood of a plaque to rupture (Sparkes et al., 2016; Rashad et al., 2018). We examined the diagnostic value of hs-CRP as a CVD predictor in patients with DM.

\section{MATERIAL AND METHODS}

This study was a hospital-based cross-sectional study conducted at 175 Military Hospital from April 2018 to March 2019 and included a total of 118 subjects between the ages of 18 and 65. Study participants were recruited using a random sampling method based on the selection criteria, which included TDM2 based on the standards of American Diabetes Association in 2014. Individuals with known stroke, cancer and decompensated chronic diseases were excluded from this study. Pregnant and lactating women and individuals who were taking drugs that affect hs- CRP levels were also excluded. Informed written consent was obtained from all subjects. The study was approved by the institutional ethics in medical research review boards and an independent ethics committee.

Date of diabetes diagnosis, age, sex, height, weight, and use of cardiac medications (anticoagulants, ace inhibitors, and statins) were abstracted from the medical records at each study visit. Body mass index $\left(\mathrm{BMI}, \mathrm{kg} / \mathrm{m}^{2}\right.$ ) was computed from height and weight measurements, and baseline diabetes duration was calculated based on date of diagnosis. $\mathrm{HbA} 1 \mathrm{c}$ was assessed at baseline and at the end of the study using a laboratory assay standardized to the Diabetes Control and Complications Trial. Serum concentrations of 
triglycerides (TG), total cholesterol (TC), high-density lipoprotein cholesterol (HDL-C) and low-density lipoprotein cholesterol (LDL-C) were assessed. Systolic and diastolic blood pressure (SBP and DBP) were abstracted from medical records at each visit. Patients examined in this study were categorized and assessed based on the classification of chronic kidney disease (Sparkes et al., 2016).

The collected data were analyzed statistically to determine the significance of different parameters by the SPSS program (v. 14.0). Normal distribution of variables was assessed by Kolmogorov-Smirnov test. The values among groups are compared using oneway ANOVA. Nonparametric Mann-Whitney tests was used for quantity variables that were not normally distributed. A P-value $<0.05$ was considered as statistically significant. Regression analysis was used to study association among parameters.

\section{RESULTS}

\section{Baseline characteristics of the study participants}

Baseline demographic characteristics for study participants are shown in Table 1. There were no differences in age and gender between studied subjects. Mean age of the participants was 60.8 years (SD: 12.1) in subjects. At baseline, more than a half of participants were confirmed by presence of several modified cardiovascular risk factors (physical inactivity, overweight and obesity, hypertension, dyslipidemia). However, the mean body mass index (BMI) and waist circumference (WC) value were not elevated.

\section{Table 1. Baseline demographic and diet characteristics of patients with type 2 diabetes (\%).}

\begin{tabular}{|c|c|c|}
\hline \multicolumn{2}{|l|}{ Parameter } & \multirow[t]{2}{*}{ P-Value } \\
\hline Age (years) & & \\
\hline male & $57.77 \pm 13.71$ & $<0.05$ \\
\hline female & $63.26 \pm 10.1$ & \\
\hline Age groups & & $<0.05$ \\
\hline$\leq 40$ & $6(5.1)$ & \\
\hline $40-50$ & $18(15.3)$ & \\
\hline $50-60$ & $36(30.5)$ & \\
\hline $60-70$ & $31(26.3)$ & \\
\hline$>70$ & $27(22.9)$ & \\
\hline Gender & & $<0.05$ \\
\hline Woman & $53(44.9)$ & \\
\hline Man & $65(55.1)$ & \\
\hline Average BMI (kg/m2) & & \\
\hline male & $22.17 \pm 2.71$ & \\
\hline female & $23.01 \pm 3.11$ & $<0,05$ \\
\hline general & $22.63 \pm 2.95$ & \\
\hline Waist circumference $(\mathrm{cm})$ & & \\
\hline male & $73.47 \pm 6.28$ & \\
\hline female & $72.48 \pm 5.46$ & $<0.05$ \\
\hline general & $72.93 \pm 5.84$ & \\
\hline Smoke & $13(11)$ & $<0.05$ \\
\hline heavy drinking & $4(3.4)$ & $<0.05$ \\
\hline Little physical activity & $78(66.1)$ & $<0.05$ \\
\hline Overweight and obesity $(\mathrm{BMI}>23)$ & $54(45.8)$ & $<0.05$ \\
\hline Hypertension & $80(67.8)$ & $<0.05$ \\
\hline Dyslipidemia & $87(73.7)$ & $<0.05$ \\
\hline
\end{tabular}


Data are expressed as mean $\pm \mathrm{SD}$, median and interquartile range, or percentage frequency [\%], as appropriate.

The studied group was characterized by hyperglycemia and elevated glycated hemoglobin: fasting serum glucose level was $11.35 \mathrm{mmol} / \mathrm{l}$ (SD: 6.15 ) and $\mathrm{HbAlc}$ was $8.07 \%$ (SD:2.40). The corresponding mean time of diabetic history was 3.12 years (SD: 2.29).

Among the 118 patients with T2DM, the prevalence of microalbuminuria and macroalbuminuria were $5.22 \%$ and $7.83 \%$, respectively.

Mean values of lipid profile parameters did not fit treatment goals recommended by 2019 ESC/EAS Guidelines for the management of dyslipidaemias: (Mach et al., 2020) (Table 2).

Table 2. Baseline characteristics of lipids profile of patients with type 2 diabetes.

\begin{tabular}{lllll}
\hline Index & Min - Max & Mean & $\begin{array}{l}\text { Compare with good control } \\
\text { value }\end{array}$ & $\begin{array}{l}\text { One sample T-Test P } \\
\text { values }\end{array}$ \\
\hline $\begin{array}{l}\text { Cholesterol } \\
(\mathrm{mmol} / \mathrm{l})\end{array}$ & $1.3-10.24$ & $5.07 \pm 1.44$ & $<4.5$ & $>0.05$ \\
$\begin{array}{l}\text { Triglyceride } \\
\text { (mmol/l) }\end{array}$ & $0.52-12.87$ & $2.64 \pm 2.07$ & $<1.5$ & $<0.05$ \\
LDL-C (mmol/l) & $0.15-6.44$ & $2.97 \pm 1.08$ & $<2.5$ & $<0.05$ \\
HDL-C $(\mathrm{mmol} / \mathrm{l})$ & $0.22-4.54$ & $1.28 \pm 0.64$ & $>1.1$ & $<0.05$ \\
\hline
\end{tabular}

Data are expressed as mean $\pm \mathrm{SD}$, median and interquartile range.

In patients with T2DM a significant increase of hs-CRP was revealed (Figure 1): mean hs-CRP value was $7.66 \mathrm{mg} / \mathrm{L}(\mathrm{SD}: 18.98)(\mathrm{P}<0.05)$.

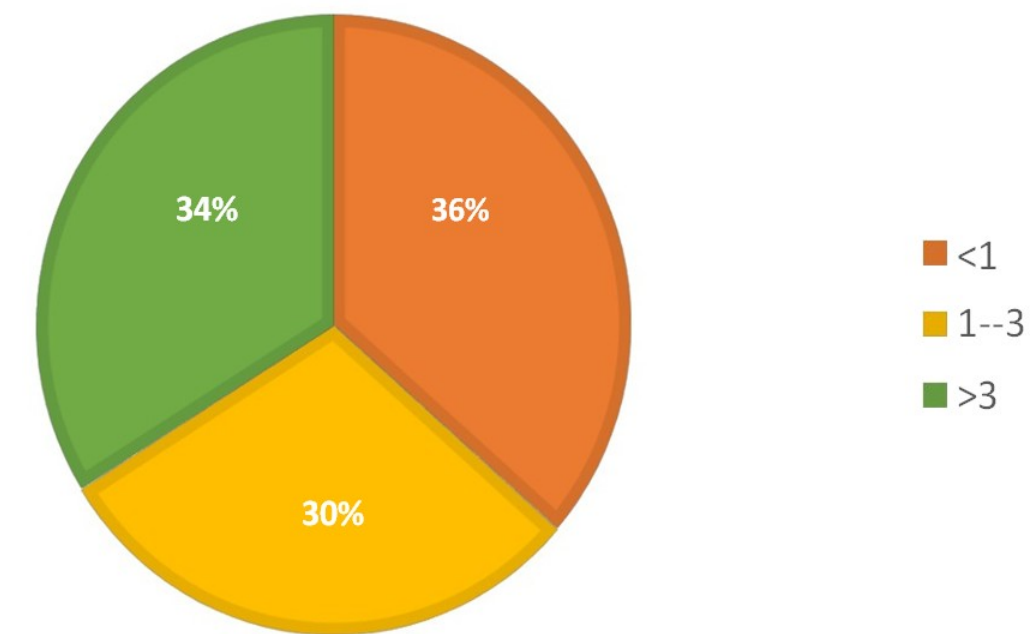

Figure 1. Rate of cardiovascular risk stratification by hs-CRP concentration.

Age in years was positively correlated with hs-CRP levels $(=0.2816 \mathrm{P}<0.01)$, while diabetes duration in years was not $(=-0.26, \mathrm{P}>0.05)$ (Figure 2$)$. 


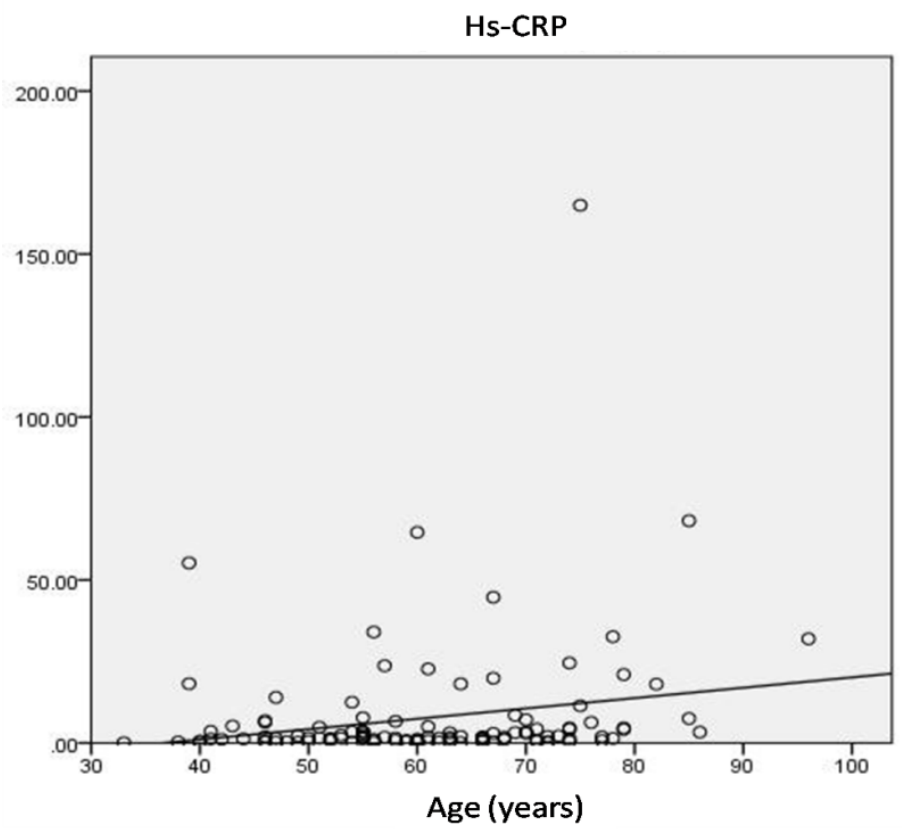

Figure 2. Correlation between hs-CRP and age.

No significant association were observed between hs-CRP level and such risk factors as SBP, FBS, HbALC, TC, TG, LDL-C. However, correlation between hs-CRP and BMI (Figure 3), HDL-C (Figure 4) were found: $(=0.233, \mathrm{P}<0.05 ;=0.29, \mathrm{P}<0.01$ ), respectively.

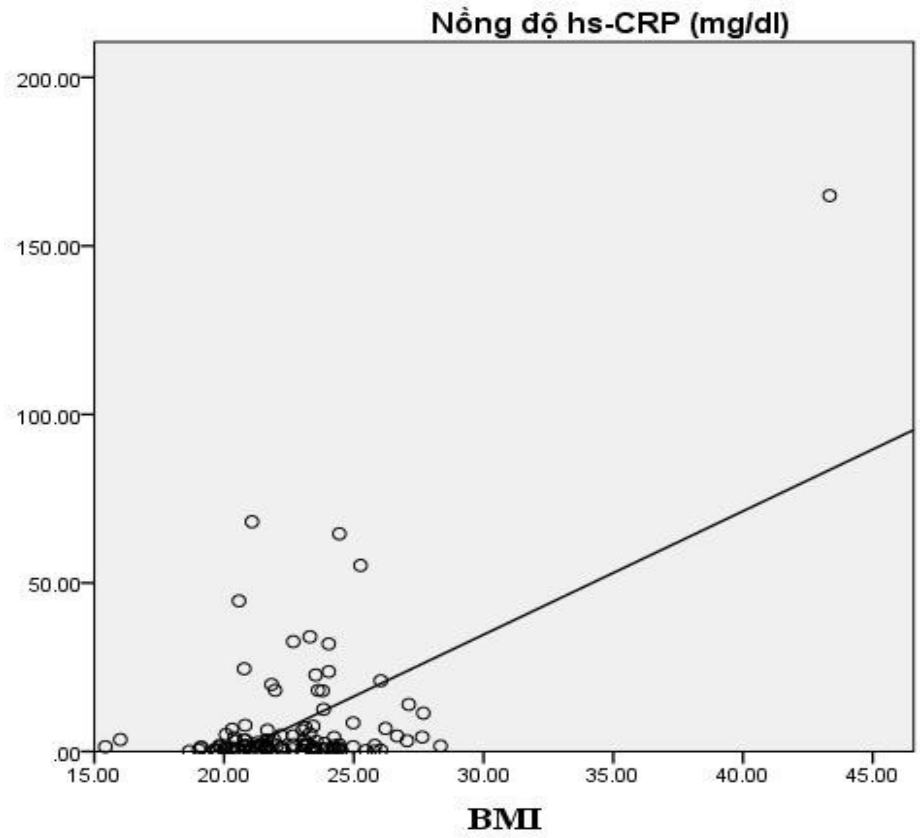

Figure 3. Correlation between hs-CRP and BMI. 


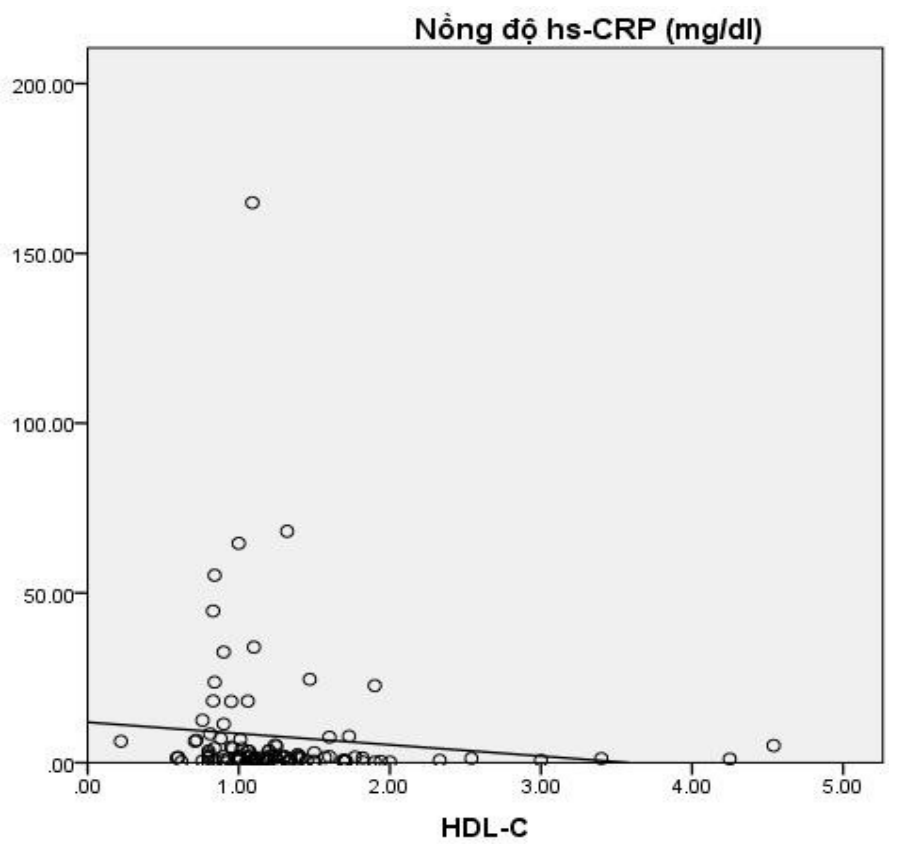

Figure 4. Correlation between hs-CRP and HDL-C.

The results of hs-CRP levels depending on diabetes duration in patients with T2DM are shown in Table 3.

Table 3. Average serum hs-CRP concentration depending on diabetes duration in patients with type 2 diabetes.

\begin{tabular}{llr}
\hline Time (years) & N & $2.15 \pm 1,67$ \\
\hline$<1$ & 25 & $7.89 \pm 21.10$ \\
$1-5$ & 79 & $10.05 \pm 16.84$ \\
$>5$ & 14 & \\
P (ANOVA) & & \\
\hline
\end{tabular}

In subjects with T2DM, no significant differences in hs-CRP levels determined by age and gender were found (Table 4). Moreover, no positive association between hs-CRP concentration and following cardiovascular risks: smoking, overweight/obesity, dyslipidemia, hypertension, proteinuria was found (Table 5).

Table 4. The average plasma concentration of hs-CRP determined by age and gender in patients with type 2 diabetes.

\begin{tabular}{llcc}
\hline Risk factors & & hs-CRP (mg/L) & P \\
\hline \multirow{2}{*}{ Age (years old) } & $>60$ & $5.31 \pm 11.85$ & $<0.05$ \\
& $<60$ & $10.10 \pm 24.10$ & $<0.05$ \\
Sex & Male & $7.26 \pm 13.68$ & $80 \pm 22.5$ \\
\hline
\end{tabular}


Table 5. Average plasma hs-CRP concentration with some modified cardiovascular risk factors in observed patients with type 2 diabetes.

\begin{tabular}{llcl}
\hline Risk factors & & hs-CRP $\mathbf{( m g} / \mathbf{L})$ & P \\
\hline \multirow{2}{*}{ Smoking } & Yes & $6.64 \pm 8.09$ & $<0.05$ \\
& No & $7.79 \pm 19.93$ & $<0.05$ \\
Overweight and obesity & Yes & $10.87 \pm 25.06$ & $<0.05$ \\
& No & $5.02 \pm 11.22$ & $<0.05$ \\
dyslipidemia & Yes & $6.73 \pm 19.39$ & $<0.05$ \\
& No & $9.55 \pm 18.98$ & \\
Hypertension & Yes & $9.77 \pm 22.54$ & $3.22 \pm 4.89$ \\
& No & $12.08 \pm 19.1$ & \\
Proteinuria & Yes & $6.90 \pm 19.22$ & \\
\hline
\end{tabular}

In patients with T2DM no significant differences in number of cardiovascular risk factors to hs-CRP plasma levels were found (Table 6). Moreover, there was no significant correlation between hs-CRP concentration and most known cardiovascular risk factors, except proteinuria (CI 95\% 1.86 - 25.10) (Table 7).

Table 6. Relationship to hs-CRP plasma levels with a combination of risk factors.

\begin{tabular}{lllc}
\hline Number of risk factors & N & Ratio (\%) & hs-CRP \\
\hline 1 & 14 & 11.86 & $2.61 \pm 4.68$ \\
2 & 35 & 29.66 & $5.20 \pm 12.77$ \\
3 & 43 & 36.44 & $8.88 \pm 14.81$ \\
4 & 25 & 21.18 & $12.16 \pm 32.85$ \\
$\mathrm{P}$ & $<0.05$ & & \\
\hline
\end{tabular}

Cardiovascular risk factors include: smoking. little physical activity. overweight. obesity. Dyslipidemia, and hypertension

Table 7. Logistic multivariate regression correlation between hs-CRP and some cardiovascular risk factors in patients with type 2 diabetes.

\begin{tabular}{llllll}
\hline Risk factor & $\boldsymbol{\beta}$ & $\mathbf{P}$ & Odds ratio (OR) & CI 95\% \\
\hline Age $\geq 60$ & 0.612 & $<0.05$ & 1.844 & 0.756 & -4.495 \\
Male & 0.096 & $<0.05$ & 1.101 & 0.412 & -2.943 \\
Smoke & 0.815 & $<0.05$ & 2.259 & 0.455 & -11.206 \\
Overweight and obesity & 0.636 & $<0.05$ & 1.888 & 0.766 & -4.658 \\
Dyslipidemia & -0.13 & $<0.05$ & 0.878 & 0.298 & -2.589 \\
Hypertension & -0.526 & $<0.05$ & 0.591 & 0.224 & -1.564 \\
Proteinuria $(+)$ & 1.924 & $<0.05$ & 6.849 & 1.869 & -25.106 \\
\hline
\end{tabular}

According to the data of the study, high hs-CRP concentration $(>3 \mathrm{mg} / \mathrm{L})$ was negatively associated with FBS levels (CI 95\% 0.69-4.04) and HbAlc (CI 95\% 0.64 - 3.47).

There was no significant difference among hs-CRP levels for mean target FBS levels $(\mathrm{P}>0.05)$ (Table 8), HbA1c levels $(\mathrm{P}>0.05)$ (Table 9), LDL-C (Table 10) and HDL$\mathrm{C}$ (Table 11) levels using ANOVA. Though, a difference between hs-CRP levels and target TC levels (Table 12) in patients with T2DM was observed. 
Table 8. Relation between hs-CRP levels and fasting blood sugar level reaching the target in the diabetes patients.

\begin{tabular}{llll}
\hline & hs-CRP $(\mathbf{m g} / \mathbf{L})$ & Mean & P ( Anova) \\
\hline fasting blood sugar level & Good $(\mathrm{n}=21)$ & $3.2 \pm 5.55$ & \\
& Permissive $(\mathrm{n}=13)$ & $9.24 \pm 19.6$ & $<0.05$ \\
& Least $(\mathrm{n}=80)$ & $8.79 \pm 21.42$ & \\
\hline
\end{tabular}

Table 9. Relation between hs-CRP concentration and reaching target $\mathrm{HbAl}$ in the diabetes patients.

\begin{tabular}{llcl}
\hline Level HbA1c & hs-CRP $(\mathbf{m g} / \mathbf{L})$ & Mean & P (Anova) \\
\hline & Good $(\mathrm{n}=36)$ & $5.25 \pm 11.95$ & $<0.05$ \\
& Permissive $(\mathrm{n}=24)$ & $13.35 \pm 35.28$ & \\
\hline Least $(\mathrm{n}=52)$ & $6.8 \pm 11.88$ & \\
\hline
\end{tabular}

Table 10. Relation between hs-CRP levels to reached targets LDL-c in the studied patients.

\begin{tabular}{llcl}
\hline & & & \\
Level LDL-C & & Mean & P (Anova) \\
\hline & Good $(\mathrm{n}=30)$ & $12.21 \pm 31.23$ & \\
Permissive $(\mathrm{n}=37)$ & $6.82 \pm 15.73$ & $>0.05$ \\
Least $(\mathrm{n}=37)$ & $4.73 \pm 8.72$ & \\
\hline
\end{tabular}

Table 11. Relation between hs-CRP levels and reaching target HDL-c levels in diabetes patients.

\begin{tabular}{llrl}
\hline & & & \\
Level HDL-C & hs-CRP $(\mathbf{m g} / \mathbf{L})$ & Mean & \\
\hline & Good $(\mathrm{n}=52)$ & $3.80 \pm 10.19$ & \\
& Permissive $(\mathrm{n}=31)$ & $12.53 \pm 31.44$ & $>0.05$ \\
& Least $(\mathrm{n}=21)$ & $9.89 \pm 14.71$ & \\
\hline
\end{tabular}

Table 12. Relation between hs-CRP levels and reacing target cholesterol levels in the diabetes patients.

\begin{tabular}{llll}
\hline & & & Mean \\
Level Cholesterol & & P (Anova) \\
\hline & Good $(\mathrm{n}=37)$ & $4.03 \pm 7.77$ & $<0.05$ \\
& Permissive $(\mathrm{n}=25)$ & $4.57 \pm 7.12$ & $14.95 \pm 31.03$ \\
Least $(\mathrm{n}=53)$ & & \\
\hline
\end{tabular}

\section{DISCUSSION}

T2DM, a highly prevalent condition, is heterogeneous with regard to its impact on cardiovascular disease risk, primarily, because of common pathogenetic link, chronic lowgrade inflammation (Nguyen et al., 2018). Hs CRP levels have received widespread attention because of a multitude of prospective studies that have shown that is one of the most known sensitive marker of inflammatory process. In this study of diagnostic value of serum CRP as biomarker of cardiovascular risk in type 2 diabetes evaluation, we found that 
hs-CRP concentration were higher in diabetic patients as compared to healthy patients. Similar reports were published by some researchers (Ebrahimi et al., 2016; Tutuncu et al., 2016; Chuengsamarn et al., 2017), whereas some studies failed to observe this difference among patients with DM and control subjects (Retnakaran, 2017), Ohkuma et al. (2017) found a direct correlation between serum levels of hs-CRP and diabetes duration, whereas our data indicate that diabetes duration does not influence serum hs-CRP.

Carbone et al. (2019) reported the relationship between hs-CRP and SBP in metabolic syndrome, while we revealed negative association among them. Previous studies have reported that FBG, LDL-C, WC and gender are independently associated with serum hs-CRP concentrations (Nishide et al., 2015; Parrinello et al., 2015; Wang et al., 2016; Zhang et al., 2016; Siddiqui et al., 2019). However, we did not find any significant difference among hs-CRP levels and FBS, HbALC, TC, TG, LDL-C. It has been suggested that this association may be noncausal. As reported, there were no evident association between hs-CRP concentration and history of smoking, whereas Siddiqui et al. (2019) showed that chronic smoking patients had significantly increased hs-CRP levels. In our study the hs-CRP values were significantly higher in diabetics who had dyslipidemia signs compared to controls $(\mathrm{p}<0.05)$.

Wang et al. (2016) and Singh et al. (2019) found similar results in studies done in many parts of the world. Its known that diabetic kidney disease develops in half of genetically predisposed patients with T2DM. Early diagnosis of kidney damage and nephroprotective treatment are the ways of preventing the disease progression (Żyłka et al., 2018). The combination of T2DM and chronic kidney disease not only increases the risk of end stage renal disease but also of cardiovascular events and all-cause mortality, with cardiovascular complications being the main cause of death in these patients. Recent evidence suggests that CRP plays a major role in the pathophysiologic processes and the course of renal injury in patients with T2DM. Similar results were revealed in our study, significant correlation between hs-CRP concentration and proteinuria levels in patients with T2DM (CI 95\% $1.86-25.10)$.

According to the criteria of ACCF/AHA (American Diabetes Association, 2016), if CRP concentrations $>3 \mathrm{mg} / \mathrm{L}$ was with "high risk", no associations with FBS levels (CI 95\% 0,69-4,04) and HbAlc (CI 95\% 0.64-3.47) were found. There was no significant difference among hs-CRP for mean target FBS levels ( $p>0.05)$, HbAlc levels $(p>0.05)$, LDL-C and HDL-C levels using ANOVA. Studies have shown that intensive LDL-lowering therapy results in a significant reduction in cardiovascular disease risk and improved outcomes (Chianeh et al., 2016, Kumar et al., 2018). Though, no significant difference among hs-CRP concentrations for mean target LDL-C and HDL-C levels were observed in our study.

\section{CONCLUSIONS}

In concussion, an apparent association between hs- CRP and high cardiovascular risk is unlikely to be causal. We conclude that hs-CRP can be used in cardiovascular risk stratification in diabetic patients with comorbid obesity and dyslipidemia. 


\title{
ACKNOWLEDGMENTS
}

The authors are thankful to 175 Millitary Hospital for financial support.

\section{CONFLICTS OF INTEREST}

\author{
The authors declare no conflict of interest.
}

\section{REFERENCES}

American Diabetes Association (2016). ADA diabetes guidelines summary recommendation from NDEI. Nat. Diabetes Educ. Initiat. 39(1): 1-46.

Carbone F, Elia E, Casula M, Bonaventura A, et al. (2019). Baseline hs-CRP predicts hypertension remission in metabolic syndrome. Eur. J. Clin. Inv. 49(8): e13128.

Chianeh YR, Prabhu K, Bhat VR, Udupa P, et al. (2016). High-sensitive C-reactive protein levels in diabetes associated with dyslipidemia. Nat. J. Phys. Pharm. Pharmacol. 6(5): 480-483.

Chuengsamarn S, Rattanamongkolgul S, Sittithumcharee G and Jirawatnotai S (2017). Association of serum highsensitivity C-reactive protein with metabolic control and diabetic chronic vascular complications in patients with type 2 diabetes. Diabetes \& Metabol. Syndr.: Clin. Res. Rev. 11(2): 103-108.

Diabetes Control and Complications Trial, \& Epidemiology of Diabetes Interventions and Complications (DCCT/EDIC) Research Group. (2016). Risk factors for cardiovascular disease in type 1 diabetes. Diabetes. 65: 1370-1379. https://doi.org/10.2337/db15-1517.

Ebrahimi M, Heidari-Bakavoli AR, Shoeibi S, Mirhafez SR, et al. (2016). Association of Serum hs-CRP Levels With the Presence of Obesity, Diabetes Mellitus, and Other Cardiovascular Risk Factors. J. Clin. Lab. Anal. 30: 672-676. DOI:10.1002/jcla.21920.

Gawlik K, Naskalski JW, Fedak D, Pawlica-Gosiewska D, et al. (2016). Markers of Antioxidant Defense in Patients with Type 2 Diabetes. Oxid. Med. Cell Longev. 2016: 2352361. doi: 10.1155/2016/2352361.

Ilyas Z, Chaiban JT and Krikorian A (2017). Novel insights into the pathophysiology and clinical aspects of diabetic nephropathy. Rev. Endocr. Metabol. Disord. 18(1): 21-28.

Kumar N, Singh VB, Meena BL, Kumar D, et al. (2018). Mild cognitive impairment in young type 1 diabetes mellitus patients and correlation with diabetes control, lipid profile, and high-sensitivity c-reactive protein. Ind. J. Endocrin. Metabol. 22(6): 780.

Lascar N, Brown J, Pattison H, Barnett AH, et al. (2018). Type 2 diabetes in adolescents and young adults. Lancet Diab. Endocrinol. 6(1): 69-80.

Li Y, Zhong X, Cheng G, Zhao C, et al. (2017). Hs-CRP and all-cause, cardiovascular, and cancer mortality risk: a metaanalysis. Atherosclerosis. 259: 75-82.

Mach F, Baigent C, Catapano AL, Koskinas KC, et al. (2020). 2019 ESC/EAS Guidelines for the management of dyslipidaemias: lipid modification to reduce cardiovascular risk: The Task Force for the management of dyslipidaemias of the European Society of Cardiology (ESC) and European Atherosclerosis Society (EAS). Eur. Heart J. 41(1): 111-188.

Morrow DA and Ridker PM (2000). C-reactive protein, inflammation, and coronary risk. Med Clin North Am. 84(1): 149-61. doi: 10.1016/s0025-7125(05)70211-x.

Sanjeevi N, Lipsky LM and Nansel TR (2018). Cardiovascular Biomarkers in Association with Dietary Intake in a Longitudinal Study of Youth with Type 1 Diabetes. Nutrients. 10(10): 1552. doi: 10.3390/nu10101552.

Nguyen CT, Lee AH, Pham NM, Do VV, et al. (2018). Habitual tea drinking associated with a lower risk of type 2 diabetes in Vietnamese adults. Asia Pac. J. Clin. Nutr. 27(3): 701.

Nguyen CT, Pham NM, Tran DV, Lee AH, et al. (2016). Lifestyle and diet in relation to risk of type 2 diabetes in Vietnam: a hospital- based case-control study. Springerplus. 5(1): 1-7.

Nishide R, Ando M, Funabashi H, Yoda Y, et al. (2015). Association of serum hs-CRP and lipids with obesity in school children in a 12-month follow-up study in Japan. Env. Health Prevent. Med. 20(2): 116-122.

Ohkuma T, Iwase M, Fujii H, Ide H, et al. (2017). Joint impact of modifiable lifestyle behaviors on glycemic control and insulin resistance in patients with type 2 diabetes: the Fukuoka Diabetes Registry. Diabetolog. Int. 8: 296-305. DOI: $10.1007 / \mathrm{s} 13340-017-0310-6$.

Parrinello CM, Lutsey PL, Ballantyne CM, Folsom AR, et al. (2015). Six-year change in high-sensitivity C-reactive protein and risk of diabetes, cardiovascular disease, and mortality. Am. Heart J. 170(2): 380-389.

Rashad NM, El-Shabrawy RM, Sabry HM, Fathy HA, et al. (2018). Interleukin-6 and hs-CRP as Early Diagnostic Biomarkers for Obesity-Related Peripheral Polyneuropathy in Non-Diabetic Patients. The Egypt. J. Immun. 25(2): $153-165$.

Genetics and Molecular Research 20 (1): gmr18730

CFUNPEC-RP www.funpecrp.com.br 
Retnakaran R, Hanley AJ, Raif N, Connelly PW, et al. (2017). C- reactive protein and gestational diabetes: the central role of maternal obesity. J. Clin. Endocrinol. Metab. 88(8): 3507-3512.

Siddiqui SS, Amir M, Singh D, Aggarwal T, et al. (2019). Cardiovascular Risks Assessment of Tobacco Smokers (Cigarette \& Bidi) using hs CRP \& Lipid Profile in Muzaffarnagar City. Int. J. Phys. 7(2): 116-118.

Singh N, Chawla HV, Bhattacharya S, Sharma V, et al. (2019). A cross-sectional study on association of highsensitivity C-reactive proteins (HS-CRP) with dyslipidemia in type 2 diabetic patients of Haryana region. Int. $J$. Healthcare Biomed. Res. 7(02): 30-39.

Sparkes AH, Caney S, Chalhoub S, Elliott J, et al. (2016). ISFM consensus guidelines on the diagnosis and management of feline chronic kidney disease. J. Feline Med. Surg. 18(3): 219-239.

Strain WD and Paldanius PM (2018). Diabetes, cardiovascular disease and the microcirculation. Cardiovasc. Diabet. 17(1): 57.

Syauqy A, Hsu CY, Rau HH, and Chao JCJ (2018). Association of dietary patterns, anthropometric measurements, and metabolic parameters with C-reactive protein and neutrophil-to-lymphocyte ratio in middle-aged and older adults with metabolic syndrome in Taiwan: a cross-sectional study. Nutr. J. 17(1): 106.

Tutuncu Y, Satman I, Celik S, Dinccag N, et al. (2016). A comparison of hs-CRP levels in new diabetes groups diagnosed based on FPG, 2-hPG, or HbA1c criteria. J. Diabetes Res. 5827041. DOI: 10.1155/2016/5827041.

Wang Z, Wang X, Chen Z, Zhang L, et al. (2016). Distribution of high-sensitivity c-reactive protein and its relationship with other cardiovascular risk factors in the middle-aged Chinese population. Int. J. Env. Res. Publ. Health. 13(9): 872.

Wang Z, Wang X, Chen Z, Zhang L, et al. (2016). Distribution of high-sensitivity c-reactive protein and its relationship with other cardiovascular risk factors in the middle-aged Chinese population. Int. J. Env. Res. Publ. Health. 13(9): 872.

World Health Organization. Global Report on Diabetes. Geneva, Switzerland: World Health Organization; 2016. apps.who.int/iris/bitstream/10665/204871/1/9789241565257 eng.pdf. Accessed November 26, 2019.

Zhang R, Dong SY, Wang F, Ma C, et al. (2018). Associations between body composition indices and metabolic disorders in Chinese adults: a cross-sectional observational study. Chin. Med. J. 131(4): 379.

Żyłka A, Dumnicka P, Kuśnierz-Cabala B, Gala-Błądzińska A, et al. (2018). Markers of glomerular and tubular damage in the early stage of kidney disease in type 2 diabetic patients. Mediators of Infl. 2018: 7659243. DOI: $10.1155 / 2018 / 7659243$ 